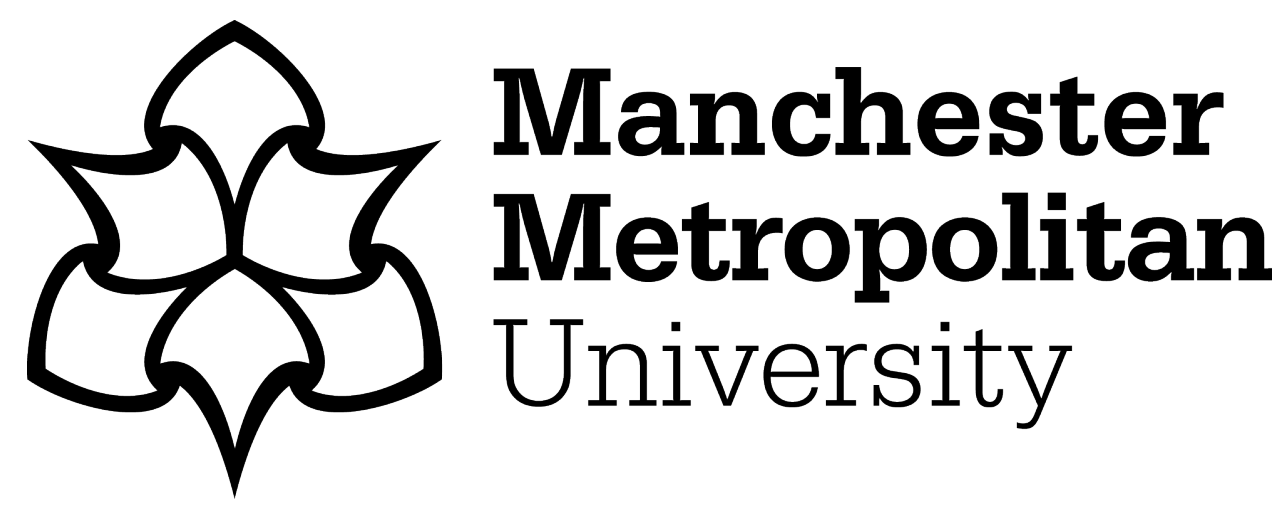

McGuire, Brendon, Parker, Lucy and Cooper, William (2001) Physical education and language: do actions speak louder than words? Physical education \& sport pedagogy, 6 (2). pp. 101-116. ISSN 1362-7120

Downloaded from: https://e-space.mmu.ac.uk/92661/

Version: Accepted Version

Publisher: Taylor and Francis

DOI: https://doi.org/10.1080/1740898010060203

Please cite the published version 


\title{
PHYSICAL EDUCATION AND LANGUAGE: DO ACTIONS SPEAK LOUDER THAN WORDS?
}

\begin{abstract}
This study examines the nature and extent to which physical education (PE) lessons can provide effective language experiences and contribute to pupils' oracy development. A base for discussion is provided by an analysis of the limited research in the area, alongside the evolving statutory requirements and reviews.
\end{abstract}

The research involved partner high schools across two Local Education Authorities (LEA's) of a university faculty of education, within North West England. The schools represented two distinct areas: an inner-city, multicultural community and a suburban, semi-rural, predominantly white community. Questionnaires were completed by 39 secondary school PE Heads of Department and follow-up, semi-structured, in-depth interviews were conducted with 3 of these teachers.

Results demonstrated that most teachers had good awareness of the language potential of the subject. Schools that had high proportions of English as an Additional Language (EAL) and other Special Educational Needs (SEN) pupils, had particularly well-developed practices. In most of these schools, National Curriculum Physical Education (NCPE) language attainment targets were being addressed and in many instances achieved, through a variety of proactive approaches, which included: question and answer sessions, feedback on performance, groupwork and other aspects of co-operative working.

\section{INTRODUCTION}

The teaching of language in schools in the United Kingdom (UK) has long been a high profile, emotive issue. Just over twenty-five years ago, the Bullock Committee (DES, 1975), investigating the teaching of English language, produced their 'landmark' report, boldly titled, 'A Language For Life', analysing language as both social and power issues. One of the main recommendations of this report was the 'non fragmentation' of language activity in schools. In the light of current anxieties expressed about children's literacy levels (Henry, 2001a; Henry 2001b; Wyse and Jones, 2001) it is perhaps prudent to accept from the outset that every curriculum area has a role to play in 'whole school' language strategies.

Since the recommendations of the Bullock Committee (DES, 1975), much research and other significant reports have been published regarding the important role of talk and use of language in the learning process, within all curriculum areas (Halliday, 1985, DES, 1987, DES, 1989, DfEE, 1998.)

Such reports and research are summarised, more recently, by Medwell et al (2001) who state that:

.... Teachers need to offer children more language to learn - more varied text types (spoken and written) a wider range of words, new 
ways of organising language, the conventions of standard written English at text, sentence and word levels. Children need to learn language. Children need to learn the language of the subjects so that they can learn the concepts of these subjects. Children also need effective oracy and literary skills so that they can have access to other subjects.

(Medwell, 2001, pp15-16)

Bullock (DES, 1975) made teachers aware of the significance of addressing issues concerned with oracy, a need that led to the formation of the National Oracy Project (NOP, 1987.) Started under the auspices of the School Curriculum Development Committee, three of the project's main aims were: to enhance the role of speech in the learning process for the 5-16 years age group by encouraging active learning, to improve pupils' performance across the curriculum, and to use it as a means to improving learning generally (NOP 1987).

The report of the Kingman Committee (DES, 1987) emphasised the importance of children's knowledge of language, as did the Cox Report (DES, 1989). Cox stated that the development of speaking and listening skills was as relevant to the curriculum as reading and writing. Consequently, when the National Curriculum for English was published in 1989, equal weighting was given to the profile components of speaking and listening, in addition to reading and writing. Cox made a clear and unambiguous statement about the presence of bilingual pupils, stating that they should be viewed as a positive resource in the classroom, rather than a potential problem, because of their knowledge of different languages.

Cox (DES, 1989) also made another strong recommendation, one which has real relevance for all curriculum areas and particularly for a subject such as $\mathrm{PE}$, perhaps hitherto regarded as being chiefly concerned with the physical domain. The report stated that the growth of the content for the English curriculum was disproportionate to the proposed curriculum time available, and so cross-curricular opportunities should be made available to develop language skills.

In 1998, the National Literacy Strategy (DfEE, 1998) was implemented in UK primary schools and the strategy will also now be introduced at Key Stage 3 from September 2001. More than a decade after Kingman and Cox, teachers are drawing attention to the patterning of language at word, sentence and text levels. Critical discussion and analysis of their work leads children to explore and understand the complexities of the English language. Varying contexts, $P E$ included, can add to the quality of children's developing language.

The National Curriculum for English (DfEE/QCA, 1999a), taught in England and Wales from September 2000, makes explicit the cross-curricular opportunities to teach language skills. Each of the programmes of study for National Curriculum subjects contains advice and guidance for teachers on how language skills can be addressed. At Key Stages 3 and 4 in the English document, it specifically includes components of the key skill of 
communication. It incorporates: contributing to a discussion, making clear and relevant contributions and listening and responding appropriately; giving a short talk with clear structure; speaking clearly and illustrating key points; and selecting, reading and summarising information, identifying the main points and lines of reasoning (DfEE/QCA, 1999a, p 8). These objectives could all be achieved in PE lessons.

In the NCPE document it states:

... . physical education provides opportunities for pupils to develop the key skills of communication, through promoting verbal and non-verbal communication skills when explaining what they intend to do, giving feedback to others, planning and organising group or team work, giving instructions and signals in a game ....

(DfEE/ QCA, 1999b, p8)

At Key Stage 3, the PE programme of study includes the statement that, "..pupils should be taught to take the initiative to analyse their own and others' work, using this information to improve its quality" (DfEE/QCA, 1999b, p3). The document then directs the teacher to a specific link with English, namely that pupils should be taught, "to help the group to complete its tasks by varying contributions appropriately, clarifying and synthesising others' ideas, taking them forward and building on them to reach conclusions, negotiating consensus or agreeing to differ." (DfEE/QCA, 1999b, p8.)

Similar links between the subjects of PE and English are made at Key Stage 4. Pertinent to what PE can offer in the promotion of oracy skills, is the guidance put forward in the NCPE document under the paragraph of 'Use of language across the curriculum':

Pupils should be taught the technical and specialist vocabulary of subjects and how to use and spell these words. They should also be taught to use the patterns of language vital to understanding and expression in different subjects.

(DfEE/ QCA, 1999b, p 37)

The document reiterates that PE teachers have a wider responsibility to develop the 'whole child' and, "...promote learning across the curriculum in a number of areas such as spiritual, moral, social and cultural development, key skills and thinking skills" (DfEE/QCA, 1999b, p8.) Hence, one main conclusion from the National Curriculum documentation is not just that PE may contribute to the development of language skills, but that it is expected so to do.

\section{Language and motor activity}

Physical Education teachers have traditionally been involved in discussions about the effectiveness and merits of PE programmes (Graham, 1990). The broad and balanced educational experiences that are compulsory for all children, illustrate that PE lessons have an important role to play in the holistic education of the child. 
It is suggested also, that appropriate early experiences of PE and sport operate as a positive predictor for future, adult participation (Curtis et al, 1999). Within this scenario, recognising the important role language has to play in the subject means good teachers are able to use PE as a vehicle for teaching an array of concepts, not just the physical, but also covering linguistic, social and cognitive development.

Despite the lack of sustained, comprehensive research into the relationship of language and PE in both the secondary and primary school curricula, previous studies have successfully established that language and motor activity are closely linked (Bearne, 1998.) It is noted that the language acquisition patterns of infants have certain parallels with the acquisition of motor skills (Yule, 1994). This point is repeated by Maude (1998) in an analysis of the links between language and physical education in the primary sector. Infants develop language skills through motor exploration and, as a consequence, motor skills are also enhanced. Maude (1998) clearly highlights this significant, entwined relationship between movement, language and physical education. As children experience physical activity they also acquire a vocabulary, syntax and structure.

The special nature of the PE environment and curriculum, means that movement and developmentally appropriate physical tasks assist language development in several key ways:

Physical activity is a natural environment for language instruction... physical activity may facilitate improved generalization of knowledge of vocabulary labels. For example, children may have learned to identify the colour red in books and among building blocks in the classroom. In physical education activities they can learn to generalize the colour red to pieces of physical education equipment such as balls, shapes, spots, tapes and paddles.

(Connor-Kuntz and Dummer, 1996, p303)

Physical education classes rarely take place in silent, static environments. Pupils who benefit from a good physical education programme are encouraged to plan their performances, discuss content and listen to the reflections of others. This is done using a variety of techniques and is commonly enhanced by the use of visual aids, with an increasing emphasis on Information and Communication Technology (ICT.) Well-planned programmes encourage many language types and communication activities, that are in nature both restricted (low word count, often with short simple commands) and elaborated (long sentences with complex syntax.)

Guildenhuys and Orsmond (1996) also suggest that good PE lessons provide real, vital and visual experiences rather than being of an abstract, inert or purely verbal nature. The concrete experiences of, say, discussing a route in orienteering or of watching and commenting on a performance in gymnastics, are tangible, common occurrences through which oracy skills can be developed. Guildenhuys and Orsmond (1996) add that language is not an abstract set of concepts just as the relationship between motor activity and 
physical education is neither vague nor unrelated. They maintain that language can be placed in context naturally and meaningfully during physical activity. The process of acquiring language is achieved, in part, through the use of social, interactive routines. For instance, the routine of planning, performing and evaluating may be used by the teacher to encourage language skills to develop alongside physical abilities.

Connor-Kuntz and Dummer (1996) stress the potential of teachers constructing teaching situations where this type of learning is most likely to occur, stating that, "Motor activities can be academically structured to provide a base for learning language" (p303.) The rewards for such precise educational provision are high. The wider, literacy concepts that are possible to be achieved through PE are those at the heart of educational practice: reading, writing, speaking and listening. Blake (1996) in a detailed analysis of the potential use and development of language through PE confirms that these are the areas that should be addressed. These concepts may be introduced through the use of:

- Task cards

- Fitness programmes

- ICT / ROM programmes

- Enhancement of map skills in OAA

- Problem solving opportunities

- Critical analysis and evaluation

- Pupil self assessments

- Notice boards

Also, in addition to these formal, teacher-constructed language opportunities, are other informal language interactions that are significant within the school environment. The exact role and impact of informal exchanges are very difficult to evaluate and quantify, but language experts testify to the value of such practice in addition to the more formal interactions:

Similarly, in the playground, teachers gain different insights when witnessing their pupils at play....it is important that teachers understand these dimensions of development because they enable teachers to plan more effectively for the needs of their children.

(Wyse and Jones, 2001, p210)

Such informal interactions are also often linked to important gender issues that have challenged PE in recent years. Dodds (1993), states that to be effective in removing the stereotypes and sexist language that have been an integral part of the education system, teachers must consider and change their interactive verbal behaviours. Dodds goes on to encourage the use of inclusive language that does not exclude pupils or display any direct gender bias. Scraton (1993) states that teachers of PE must model and directly intervene where language is not suitable, whilst Talbot (1993) contends that in order to overcome such problems, a whole change in the culture of the delivery of PE lessons needs to be implemented. 
Central to the focus provided by existing literature on the wider theme, is the suggestion that useful language skills and experiences can derive from physical activity. However, with the current concern raised in PE circles about reduced activity levels, does enriched language activity necessarily mean that less time is spent on improving children's movement competence? In previous research with pre-school children, the suggestion has been that there is no decrease in activity levels but a definite increase in language competence (Connor- Kuntz \& Dummer 1996). Thus, planned language input is vital if a physically educated young person is to maximise the potential each lesson offers for learning. The analysis of language in PE classes undertaken by the School Curriculum and Assessment Authority (SCAA, 1997) reveals that language is a vital part of becoming physically educated, recognising too that $\mathrm{PE}$ is an important area for language development.

\section{EAL pupils and physical education}

Schools in the UK are centres for language aptitude and attitude (Crystal 1995). They are swift in their support of good language use and its development throughout the curriculum. Within these centers, bi-lingual and multi-lingual pupils represent significant groups. Language issues for these students have at times been shrouded in controversy. Moreover, It has been claimed that EAL pupils were not a central concern when the National Curriculum was originally devised (Carter, 1995).

Analysis of the EAL issue in the 1970's and 1980's, suggests that withdrawal from mainstream education was the norm, yet, interestingly, integration was customary in PE lessons (Burgess \& Gore 1990). Daley (1988) suggests that the 'unsculpted' curriculum and 'unsophisticated' language patterns in PE classes, posed few problems for EAL learners, adding that PE is one of the areas in which EAL students often become proficient in both subject content and language. Also, another factor that may contribute is the specific technical language used in the subject. The context, purpose, repetition, reinforcement and minimal focus add to very favourable opportunities for language development. This, juxtaposed the belief that optimum language learning occurs in high motivation/ low anxiety situations, means that physical education appears to be an ideal environment for language acquisition among EAL pupils. In more recent years then, it may be fair to state that within wider discussions of children's literacy the needs of bi-lingual and multi-lingual learners have been given higher priority. However, within PE this issue is as yet relatively unexplored.

\section{METHOD}

Eighty 'partner schools' were randomly selected from the Education faculty compendium of the university where the study was based. Questionnaires, comprising open and closed questions, were sent to the Heads of PE in each of these schools. The schools are situated within two LEA's. In total, thirty-nine schools (with 11-16 or 11-18 years, age-range of pupils) responded to the questionnaire and Heads of PE from three schools agreed to follow-up, oneto-one, in-depth interviews. The LEA's spanned two main geographical areas, 
which are socially and culturally very distinct. The first LEA (inner-city) may be summarised as representing a multicultural, inner-city conurbation, where many schools have a significant number of EAL/SEN pupils. The area has very high levels of social deprivation. The second LEA (suburban) represents a semi-rural area, having a relatively higher proportion of affluent households, with many parents who are of professional / managerial status. It is a predominantly white community.

In the early stages of the questionnaire, simple, quantitative data were requested. These initial sections adopted a Likert-style response scale, to permit easy comparability between answers. To avoid the risk of compartmentalising, open questions were then used to enable respondents to answer in ways that suited their frame of reference (May, 1997.)

Semi-structured interviews were also used to enable the interviewer to probe beyond answers given in the questionnaire, seeking both clarification and elaboration of key points. Interview questions were framed in four broad areas:

- Current attempts within the school to develop children's language skills through PE, in the light of National Curriculum requirements.

- Specific language work in PE, with EAL and other SEN pupils who have Individual Education Plans (IEP's.)

- The technical language of the subject and the PE environment.

- The cross-curricular transfer of language skills involving PE.

It was planned that the information retrieved from this process was as near to actual practice and reality as possible. Conversations were allowed to flow if they were producing relevant information, resulting in qualitative, richly descriptive data. All interviews took place in the school setting. These were recorded and subsequently transcribed.

\section{RESULTS AND DISCUSSION}

\section{Can PE teachers positively affect pupils' language growth?}

Overall, $73 \%$ of the teachers surveyed believed that meaningful language development was possible during PE lessons. Within the inner-city LEA, questionnaire data revealed that several steps were already being taken to improve children's language competency in PE. This was occurring mainly through:

- Attention to the accuracy and clarity of instructions being given in task requirements.

- Feedback to pupils about performance.

- Attempts to increase children's vocabulary by introducing new words, always answering in complete sentences etc.

- Groupwork and other tasks that incorporate a high emphasis on cooperative play.

- Other situations that afford opportunities for language growth such as focusing on technical language, discussion of Health and Safety issues and displaying appropriate notice-board material. 
Within the suburban LEA, there was slightly less awareness of the potential of the subject to achieve such wide objectives although the key areas of feedback, giving instructions, question and answer situations etc. were all being used to good effect. Strong emphasis was given from staff in both LEA's, to the ways in which tasks were explained to children. This was typified by one questionnaire response, which stated:

The most important thing is that they are given tasks and have to respond. That, in a language sense, means they have to clarify their thoughts into language that everyone can understand.

Most staff also placed emphasis on the task-driven nature of the National Curriculum, particularly the Planning, Performing and Evaluating (PPE) cycle, and the examination syllabi. Through such work, staff felt that language skills were being developed in positive ways. Many teachers were already planning for such development. One said, "We will deliberately set up situations in which we would encourage that to happen." Language development is a generic part of good physical education lessons. Most teachers in this study would appear to accept that language development is not only an implicit product of PE, but also that, "Language is a significant factor in becoming physically educated and physical education is an important medium for enhancing language". (Maude,1998, p.228)

When clarifying the advantages of teaching language concepts through PE, teachers also repeatedly discussed the key area of activity level. As Daley (1988) noted, the fact that the primary focus is on physical activity and motor skill development means that language development is not an explicit issue. Language can be used, adjusted and reapplied using the context, repetition and reinforcement idea.

The remaining $27 \%$ of the respondents were undecided as to whether PE had the responsibility or potential to greatly influence children's language skills, still a somewhat surprising figure given that both legislation (DfEE/QCA, 1999a, DfEE/QCA, 1999b) and research (Bearne, 1998) clearly state otherwise. A perception that $P E$ time was being diminished was the main reason given for this reluctance to commit to the notion of language acquisition through physical education. One teacher asked, "More language work, wouldn't that impinge on physical skill development?"

How the PE environment can be advantageous to good language growth. The vast majority of teachers in the study were aware of the fact that when a lesson was going well and anxiety was reduced, the environment could be favourable for language growth. A typical comment was, "I think that it's because our specific terms are interspersed with long periods of performance, it's not as intense as elsewhere." Another staff member added, "It definitely gives them more confidence to speak and listen. I think that it's about control. In PE they learn to control their bodies, this perhaps develops further into other areas of control." 
The current orders of the National Curriculum (DfEE/QCA, 1999a) stipulate that all pupils must be taught to express themselves in speech. Staff who were committed to developing children's oracy skills through PE, clearly accepted that there is a need for pupils to talk as well as listen, highlighting the significance of the dynamic, communicative environment. Blake (1996) states that there are many teaching situations through which pupils can gain a 'shared meaning' and become good listeners. Many staff from both LEA's were clearly used to thinking about these possibilities and had already incorporated them into their working practices. One PE teacher, when interviewed, exemplified this when she said:

I'm a firm believer in having teaching situations in which people can become better listeners and interpreters.... It's common, you see children who are unable to listen. It's a common misconception that all pupils can listen, most hear, how many listen?

Another developed the point further by saying:

I think that the environment itself depends upon the style of the teacher. A didactic style, 'watch me, copy me, do it' approach is going to have a limited effect on pupils' language development. If the teaching style is much more reciprocal and there is a constant flow of communication then the environment will be more productive. In a situation where pupils have to work in groups, they depend on others, they have to communicate and use language specific to PE and the lesson. The environment is one of the important things, the teaching style in the environment probably the most important.

Pupils who are physically educated are able to recognise appropriate stimuli and then make attempts, using the vocabulary of physical education, to communicate their findings. The PE environment still presented difficulties though, common to all curriculum areas, when developing pupils' language skills. This was illustrated when one teacher said, "When we ask them things, verbally they're very weak. They say 'Like 'er, the thingime, oh, you know Miss, the effort .... we did it last week!'"

Despite this, the use of language enhancing aids, primarily designed to complement the PE programme, were greeted with eagerness by pupils. The experience of staff suggested that 'favourites' of pupils were the use of computers during Heath Related Activity sessions and use of ICT in notice board displays. The significance being attached to ICT here, suggests that there is rightful, continued emphasis on the subject's relationship with PE (see TTA, 1999) and its contribution to pupils' language development.

Does PE help the language development of EAL and other SEN pupils?

The majority of teachers from the inner-city LEA were more used to teaching EAL pupils than in the suburban LEA. They also had a higher percentage of pupils who came to them with other SEN's. Most responses from this group of teachers showed clear perceptions about how they enhance children's language skills, through the subject: 
Yes, many of our pupils need help. We're actually looking at an intake that, on a year-to-year basis has up to $40 \%$ SEN pupils of one kind or another. That doesn't necessarily mean they're statemented, but pupils who are coming in after KS2 show a level of special need. Very often that is with English. Urdu becomes an option at KS4, although I would not say that the percentage of EAL kids was any greater than the other special needs. But it's true to say that we have well above the average numbers who do need their basic skills developing. We do everything we can.

The same teacher described the proactive response that his school was already making to overcome such challenges:

We do everything we can to cope with poor literacy levels among children coming to us. For example over the summer holidays the Year 6 pupils come in and have a chance to take part in the 'Flight Start Programme'. It is a literacy and language-based programme taking place for three weeks. Teachers give up their holidays for three weeks and try to give them a flying start. It's usually well supported by the community and we feel it makes a difference.

As well as embracing a differentiated approach to learning within its schools, and an avowed commitment to social inclusion (SEU, 1998, SEU, 1999), Britain is also a multicultural society where the National Curriculum is delivered through the medium of English. In this study, PE staff working in multicultural schools within the inner-city LEA, were particularly mindful of their responsibility to equip all children, including those whose first language is not English, to develop language awareness. Positive language experiences were seen as a necessity in every area of the curriculum, and for the child who is learning English as an Additional Language the PE domain was viewed as being of considerable significance.

However, the size of the challenges facing teachers working with EAL/SEN pupils was considerable and again evidenced by this comment:

About 33\% of our current Year 7 intake have a reading age of three or more years below their chronological age. That has stayed constant for around three or four years. They're the children who have real problems in the language and literacy department. They're split into two groups, $Q$ and $R$, and have an extra English lesson per week. They have classroom assistants with them as much as possible to give them that little bit of help. Some of our children have difficulty expressing themselves in any language medium and need all the support that they can get.

In recent years though, schools that have well-developed whole-school language policies, have started to acknowledge some of the many positive experiences and outcomes that PE can offer EAL pupils and the efforts being made by staff to help such children. This study showed that staff were aware 
that, when taught well, with low anxiety levels among pupils, PE could be a most useful subject for EAL and other SEN pupils. It was recognised as a valuable, integral part of schools' wider language policies aimed at equipping pupils to access the full curriculum. PE was identified as providing context, purpose, repetition, reinforcement and minimal focus and these conditions facilitate language acquisition. The physical and verbal language within PE also act in a complementary way and, again, teachers highlighted this point. There was repeated discussion of how a knowledgeable teacher might break down skills into components that are easy for pupils to grasp, demonstrating technique through gesticulation and attaching word labels to these movements.

There would seem then, within this sphere, to be very good work going on in some multicultural schools that is as yet largely unrecognised in either the PE or English language research literature.

\section{Other ways in which PE can aid language growth}

Teachers also recognised that the existence of a technical vocabulary and tangible motor experiences within PE, provides a multitude of opportunities to develop competent language use among all pupils:

In a GCSE group where we are doing, let's say, antagonistic muscle action, a kid will simply remember the term because of the biceps/triceps action and nothing else, it's a tag.

Other examples used to demonstrate this point were the shortening of the gastrocnemius and the effect of intense exercise through physical reactions. They are visible and easily recalled, while personal experience lends itself well to the scenario. Argyle (1988) suggests that the body is an illustrator. In essence it could be contended that it enhances the reality of learning making it inevitable and more definitive. These concrete experiences are of vital significance, whilst requiring persistent reinforcement.

Further, SCAA's (1997) investigation into language development through physical education and also that by Connor-Kuntz \& Dummer (1996), concluded that planned intervention and language input develops both motor and language ability. Language is a natural and unequivocal component of PE. Disassociation would detract from the holistic experiences that PE can provide. Perspective and expertise were seen as the key factors by those staff who were fundamentally committed to developing a 'language across the curriculum' approach through PE:

Yes, it's planning and organisation, I think that it would take a fool not to understand that the bottom line is participation and performance. You simply have to think about it, it's down to good planning.

Staff also focused on the language development that was derived from examination requirements: 
A lot of the language development that we are looking for, certainly at $K S 3$, I guess no less at KS4 and GCSE, is terminology, so that they can speak in terms related to PE. The push towards examination status has led to the increased use of even more specific terms, quite complex terms that pupils need to learn and understand. So there's that aspect as well.

Consistent across both LEA's was the notion that no one area of the PE programme of study can develop language growth more successfully than any other. One teacher thought that games was the key, whilst another favoured gymnastics. The implications of body language and interpretation in dance, or the team skills of Outdoor and Adventurous Activities (OAA), were areas where potential was still not fully developed. Such areas merit future focus since the scope to develop language in these situations is clearly possible.

The less formal, 'hidden curriculum' interactions were also identified as being useful to pupils' language growth:

We have a recreational programme in the upper school where they can do more leisurely activities. Snooker, climbing, bowling, you know the kind of thing. Small groups go off-site with staff and we have found that it gives the staff a chance to talk to the pupils and vice-versa, in a situation well away from the confines of the school. There's less pressure and communication tends to be better. Everyone learns an awful lot. It's just another environment in which language and communication is practised and developed, perhaps informally... a bit like PE!

\section{CONCLUSION}

Through this study it is noted that the precise relationship between PE and language was perceived somewhat differently between teachers in the two districts. The inner-city LEA, faced with the challenges and opportunities that teaching EAL/SEN pupils bring, generally had a wider, richer range of responses than the suburban LEA. Their pupil intakes had necessitated that they develop a more vigorous approach to the concept of, "language across the curriculum.' This represented language acquisition through such features as feedback, task requirements, questioning techniques and vocabulary input.

Responses from the suburban LEA related more to the teachers and their input, rather than stressing the oracy needs of individual pupils, particularly those with special educational needs. Pupils' levels of literacy, focusing on the area of oracy, were perceived as 'good' and in some instances there was little emphasis on developing this further through PE.

Generally, there was no consensus of opinion as to what were the potentially language-rich activities in PE. Also, significantly, teachers did not draw a distinction between the experience of male and female pupils. There was little awareness of whether language growth was facilitated more for one sex than the other within the subject. Both points strongly merit further research. 
However, viewed overall, there are encouraging signs from this study that many teachers are already positively impacting upon children's language development through physical education. This is in line with the National Curriculum which suggests that spoken and written English should be developed in, "..all subjects" (DfEE/QCA, 1999a, p37.) The 73\% of staff who felt that Physical Education definitely has the potential to aid the development of pupils' language skills, were already using a variety of approaches to achieve their aims:

- Task requirements, with particular emphasis on the PPE cycle

- Question and answer sessions

- Feedback on performance

- Conscious efforts to widen pupils' vocabulary

- Differentiated language

- Groupwork and other aspects of co-operative working

- Notice boards displays

- Other interactions (Health and Safety issues, dispelling stereotypes etc)

- A targeted approach to the particular needs of EAL and other SEN pupils

As the emphasis on literacy among schoolchildren continues to remain at the pinnacle of the current government's agenda for education, it is vital that PE accepts the challenges created. The majority of staff involved in this study, were interested in the topic, gave insightful responses and were clearly working hard to improve their input in this key area. Many PE departments had already re-evaluated the very ways in which they interact with their pupils, in order to meet the requirements of the National Curriculum. Where differences were apparent, between individual authorities and their teachers, it would perhaps be appropriate to suggest that there is the need to disseminate good practice among the wider PE audience. Some schools were undoubtedly making exceptionally strong contributions to children's language growth, primarily through PE lessons but also through the enrichment activities and informal interactions that surround them.

In an 'initiative overload' culture, where it might be easier to avoid responsibility for an issue perhaps not initially thought of as pertaining to $P E$, it is surely to the credit of these teachers that the subject is now being delivered in such a way as to help children acquire language competence. Language is power and the child who can use it well can access the school curriculum more fully and the rewards and entitlement that successful study brings. As physical education continues to evolve at the start of the new century, its range and complexity grows. Whilst the subject has long been about more than just the physical domain, it is appropriate that we now start to identify its potential to contribute, meaningfully, to vital, wider educational issues such as literacy. 'Actions' and 'words' are no longer separate entities within physical education, rather they can be shaped to co-exist within an enriched environment that offers exciting educational opportunities. 


\section{ACKNOWLEDGMENTS}

The authors would like to thank two anonymous referees for their helpful advice, which we feel has led to a more useful, informative document being produced.

\section{ADDRESS FOR CORRESPONDENCE}

Please address all correspondence to: Brendon McGuire, Manchester Metropolitan University, Crewe and Alsager Faculty, Department of Exercise and Sport Science, Alsager Campus, Hassall Road,

Alsager. Cheshire. UK. ST7 2HL. Email: b.mcguire@mmu.ac.uk 


\section{REFERENCES}

Argyle, M. (1988). Bodily communication. London, Routledge.

Bearne, E. (1998). Making progress in English. London, Routledge.

Blake, B. (1996). Use of language within the National Curriculum for Physical

Education, Bulletin of Physical Education, 32:3, pp 6-18.

Burgess, A and Gore, L. (1990). The move from withdrawal ESL teaching to mainstream activities are necessary, possible and worthwhile: bilingual learners and the mainstream curriculum. London, Falmer Press.

Carter, R. (1995). Keywords in language and literacy. London, Routledge.

Connor-Kuntz, F.J. \& Dummer, G.M. (1996). Teaching across the curriculum. Language enriched physical education for pre-school children. Adapted Physical Activity Quarterly, 13: 3: 302-315.

Crystal D. (1995). The Cambridge Encyclopedia of Language. Cambridge, Cambridge University Press.

Curtis, J. McTeer, W. and White, P. (1999). Exploring Effects of School Experiences on Sport Participation in Later Life. Sociology of Sport, 16: 348365.

Daley D, (1988). Language Development Through Physical Education. British Journal of Physical Education, 19:3:132-33.

Department for Education and Employment, (1998) The National Literacy Strategy Framework for Teaching. London, HMSO.

Department for Education and Employment and the Qualifications and Curriculum Authority. (1999a) The National Curriculum Handbook for Teaching English, Key Stages 1, 2, 3 and 4. Department for Education and Employment/Qualifications and Curriculum Authority. London, HMSO.

Department for Education and Employment and the Qualifications and Curriculum Authority. (1999b). Physical Education. The National Curriculum for England. Department for Education and Employment/Qualifications and Curriculum Authority. London, HMSO.

Department of Education and Science. (1975). A Language for Life: Report of the Committee of Inquiry (The Bullock Report). London, HMSO. 
Department of Education and Science. (1987). Report of the Committee of Enquiry into the Teaching of English Language (The Kingman Report). London, HMSO.

Department of Education and Science and the Welsh Office. (1989). English for Ages 5-16 (The Cox Report). York, National Curriculum Council.

Dodds, P. (1993). Removing the ugly 'isms' in your gym. Thoughts for teachers on equity. In: Evans, J. (Ed.), Equality, Education and Physical Education. London, Falmer Press, pp 28-42.

Gildenhuys, C.A. and Orsmond, C.P. (1996). Movement and second language acquisition: the potential and method. Sport Education and Society, 1:1:103115.

Graham, G. (1990). Physical Education in US Schools. Journal of Physical Education and Dance, 61:2:35-39.

Halliday, M. (1985) An Introduction to Functional Grammar. London, Arnold.

Henry, (2001a) Maths and literacy on course but writing still trails behind. Times Educational Supplement. London, TSL Educational Ltd. July 13, 2001, p3

Henry, (2001b) We're realy grate at spelling, say young. Times Educational Supplement. London, TSL Educational Ltd. August 17, 2001, p3

Maude, P. (1998). I like climing, hoping and biking: the language of physical education. In, Bearne, E. Making Progress in English. London, Routledge. pp228-240.

May, T. (1997). Social Research. Buckingham, Oxford University Press.

Medwell, J., Wray, D., Minns, H., Griffiths, V., Coates, E., (2001) Achieving QTS. Primary English - Teaching Theory and Practice. Exeter, Learning Matters.

National Oracy Project. (1987). Teaching, Talking and Listening in Key Stage 1. York, National Curriculum Council.

Schools Curriculum and Assessment Authority. (1997). Physical Education and the Use of Language: KS 3 \& 4. Middlesex, SCAA Publications:1.

Scraton, S. (1993). Equality, Co-education and PE in Secondary Schools. In Evans, J. (Ed), Equality, Education and Physical Education. London, Falmer Press, pp139-153.

Social Exclusion Unit. (1998). Bringing Britain Together. London, HMSO. 
Social Exclusion Unit. (1999). Bridging the Gap. London, HMSO.

Talbot, M. (1993). A Gendered Physical Education: Equality and Sexism. In, Evans, J. (Ed.) Equality, Education and Physical Education. London. Falmer Press, pp 74-90.

Teacher Training Agency (1999) Using Information and Communications Technology to meet teaching objectives in physical education initial teacher training. London, Teacher Training Agency, 50/5-99.

Wyse, D. and Jones, R. (2001). Teaching English, Language and Literacy. London, Routledge.

Yule, G. (1994). The Study of Language. Cambridge, Cambridge University Press. 